\title{
Accelerated fetal growth in early pregnancy and risk of preterm birth: a prospective cohort study
}

\author{
Evangelia Elenis $^{1 *} \mathbb{D}$, Anna-Karin Wikström ${ }^{1}$ and Marija Simic ${ }^{2}$
}

\begin{abstract}
Background: Preterm birth (occurring before 37 completed weeks of gestation) affects 15 million infants annually, $7.5 \%$ of which die due to related complications. The detection and early diagnosis are therefore paramount in order to prevent the development of prematurity and its consequences. So far, focus has been laid on the association between reduced intrauterine fetal growth during late gestation and prematurity. The aim of the current study was to investigate the association between accelerated fetal growth in early pregnancy and the risk of preterm birth.
\end{abstract}

Methods: This prospective cohort study included 69,617 singleton pregnancies without congenital malformations and with available biometric measurements during the first and second trimester. Estimation of fetal growth was based on measurements of biparietal diameter (BPD) at first and second trimester scan. We investigated the association between accelerated fetal growth and preterm birth prior to 37 weeks of gestation. The outcome was further stratified into very preterm birth (before 32 weeks of gestation) or moderate preterm birth (between 32 and 37 weeks of gestation) and medically induced or spontaneous preterm birth and was further explored.

Results: The odds of prematurity were increased among fetuses with accelerated BPD growth (> 90th centile) estimated between first and second ultrasound scan, even after adjustment for possible confounders (aOR 1.36; $95 \% \mathrm{Cl} 1.20-1.54)$. The findings remained significant what regards moderate preterm births but not very preterm births. Regarding medically induced preterm birth, the odds were found to be elevated in the group of fetuses with accelerated growth in early pregnancy (aOR 1.34; 95\% Cl 1.11-1.63). On the contrary, fetuses with delayed fetal growth exhibited lower odds for both overall and spontaneous preterm birth.

Conclusions: Fetuses with accelerated BPD growth in early pregnancy, detected by ultrasound examination during the second trimester, exhibited increased odds of being born preterm. The findings of the current study suggest that fetal growth in early pregnancy should be taken into account when assessing the risk for preterm birth.

Keywords: Fetal growth, Preterm birth, Ultrasound, Early pregnancy, Induction of labor

\footnotetext{
*Correspondence: evangelia.elenis@kbh.uu.se

'Department of Children's and Women's Health, Uppsala University, Uppsala University Hospital, SE-751 85 Uppsala, Sweden

Full list of author information is available at the end of the article
}

(C) The Author(s). 2020 Open Access This article is licensed under a Creative Commons Attribution 4.0 International License, which permits use, sharing, adaptation, distribution and reproduction in any medium or format, as long as you give appropriate credit to the original author(s) and the source, provide a link to the Creative Commons licence, and indicate if changes were made. The images or other third party material in this article are included in the article's Creative Commons licence, unless indicated otherwise in a credit line to the material. If material is not included in the article's Creative Commons licence and your intended use is not permitted by statutory regulation or exceeds the permitted use, you will need to obtain permission directly from the copyright holder. To view a copy of this licence, visit http://creativecommons.org/licenses/by/4.0/ The Creative Commons Public Domain Dedication waiver (http://creativecommons.org/publicdomain/zero/1.0/) applies to the data made available in this article, unless otherwise stated in a credit line to the data. 


\section{Background}

Preterm delivery, i.e., birth prior to 37 gestational weeks, complicates $4-13 \%$ of deliveries worldwide and is the predominant cause of neonatal morbidity and mortality, having an impact on approximately 15 million infants annually [1-3]. Preterm born infants have a higher risk for adverse outcomes primarily during the neonatal period; however, harmful effects have been described to extend even at later life stages, leading to attention deficit disorders and learning impairment in childhood $[4,5]$.

Previous research has described that the etiology and timing of preterm birth is multifactorial and several projects have focused on fetal growth, usually attempting to detect fetuses at increased risk of growth restriction. In contrast, only few reports have described the effect of increased fetal size at birth and spontaneous preterm onset of labor; in a population-based, as well as a hospitalbased registry study performed in Sweden and Canada respectively, the authors demonstrated an increased risk for prematurity among fetuses with birthweight exceeding the expected $[6,7]$.

Despite the previous presumption that biological variation in fetal growth is minimal in early pregnancy and that abnormal fetal growth manifests at a later stage, there have been a number of studies showing the impact of fetal growth during early gestation on adverse pregnancy outcomes [8-11]. However, only few of them focused on accelerated fetal growth patterns among pregnancies with preterm birth. Lampl et al. followed fetal growth in 3927 pregnancies from gestational week 16 up to spontaneous birth and observed an increased risk for prematurity among fetuses with accelerated growth in the second trimester [11]. Pedersen et al. investigated fetal growth in 8215 early singleton pregnancies and reported an increased risk of preterm birth among fetuses with accelerated fetal growth, with results almost reaching statistical significance [10]. Hence, in order to overcome possible statistical challenges and enhance clinical relevance, we decided to perform a study with serial ultrasound measurements in a large, low risk obstetric population.

The primary aim of the present study was to investigate whether accelerated fetal growth, as assessed by BPD measurements, in the first half of pregnancy influenced the odds of preterm birth overall. The secondary aims were to further explore whether fetal growth differed between i) moderate and very preterm birth, as well as ii) spontaneous and medically induced preterm birth.

\section{Methods}

\section{Study design and population}

The study design is that of a longitudinal cohort study with prospectively collected data originating from a population-based obstetric database. The information gathered regard data on maternal, delivery and infant characteristics from all antenatal, ultrasound, delivery, and postnatal care units in the counties of Stockholm and Gotland in Sweden. Information about maternal reproductive history, lifestyle habits, height, weight, and state of health are usually recorded by midwives at the first antenatal visit and during pregnancy. Biometric measurements used in the study were collected from all ultrasound units in the region, and information about pre-gestational maternal diabetes and chronic hypertension, was obtained from standard delivery charts as well as diagnoses at discharge from the delivery hospital.

Singleton pregnancies $(72,309)$ from the population area of the study with available data on biometric measurements in the first and early second trimester between January 1st, 2008 and October 22nd, 2014 were included in the study sample. Pregnancies with congenital malformations $(n=2495)$ [International Classification of Diseases tenth revision (ICD-10) codes Q00-Q99)] or stillbirths $(n=197)$ were excluded, resulting in a final study population of 69,617 singleton pregnancies.

\section{Exposure}

The study exposure regarded differences in fetal biometric parameters, such as the biparietal diameter (BPD), measured by ultrasound scan during the first half of pregnancy. The Swedish Association for Obstetrics and Gynecology (SFOG) dictates that fetal BPD should be measured from the outer edge of the proximal parietal bone to the inner edge of the distal parietal bone at the level of thalami and septum pellucidum and performed by specially trained midwives according to a standardized protocol [8]. Firstly, we estimated gestational age based on biometrical measurements obtained at first trimester ultrasound scan (i.e. the combined ultrasound and biochemical screening test, CUB). Next, we related the observed fetal size at the second scan to the expected size estimated on the basis of the first trimester scan. At both first trimester $(11+0$ to $13+6$ weeks of gestation) and second trimester $(14+0$ to $21+0$ weeks of gestation) ultrasound examinations, gestational age was extrapolated from the formula by Selbing (gestational age $=58.65+1.07 \times \mathrm{BPD}+0.0138 \times\left((\mathrm{BPD})^{2}\right)$. Expected gestational age at second trimester scan was calculated by adding number of days between the two examinations to the observed gestational age at first trimester scan. The difference between observed and expected gestational age at second trimester scan, was expressed in $\mathrm{z}$ scores $\left(\mathrm{z}=\frac{X-\mu}{\sigma}\right.$, where $\mu$ equals the mean and $\sigma$ equals the standard deviation). The individual $\mathrm{z}$ scores were transformed into centiles and fetuses with growth more than the 90th percentile were defined as 
having accelerated growth, while fetuses with growth between the 10th and 90th percentile were considered as appropriate and used as the reference group. Fetuses with growth smaller than expected $(<10$ th percentile) were considered to be of delayed growth.

\section{Outcome}

The outcome measure was overall prematurity (i.e. birth at $<37+0$ weeks). Furthermore, we analyzed the odds for very preterm birth (birth at $<32+0$ weeks) and moderate preterm birth (birth between $32+0$ and $36+67+$ 0 weeks). Preterm births with clinician-initiated obstetric interventions, as opposed to spontaneous preterm births, were defined as medically induced preterm births and included prelabor $\mathrm{C}$-sections and induced labors.

\section{Covariates}

Pregnancy characteristics collected from the woman's medical records regarded maternal age at first antenatal visit (15-35 years or 36-55 years), maternal height (130$154 \mathrm{~cm}$ or $155-200 \mathrm{~cm})$, BMI at early pregnancy $(<$ or $\geq$ $30 \mathrm{~kg} / \mathrm{m}^{2}$ ), primiparity (yes/no), smoking at early pregnancy (yes/no), use of in vitro fertilization (IVF) for the current pregnancy (yes/no), pre-gestational diabetes mellitus (yes/no), chronic hypertension (yes/no) and male fetal gender (yes/no). Pre-pregnancy diabetes mellitus was defined by the ICD-10 diagnosis codes O240, O241, while chronic hypertension was defined as treatment with antihypertensive medication at first antenatal visit and/or ICD-10 diagnosis code indicating chronic hypertension $(\mathrm{O} 10, \mathrm{O} 11)$ developed at any time point before the 20th gestational week. ICD codes were provided by the responsible doctor at discharge from the hospital after delivery, while information regarding blood pressure measurements, proteinuria, and medication was provided by midwives at antenatal care or at the hospital before delivery. Information on fetal gender was collected from delivery charts. Maternal country of birth was divided into Sweden, other Nordic countries (i.e., Norway, Denmark, Finland, and Iceland), and non-Nordic countries. Information on paternal characteristics was not available in the database.

\section{Data analysis}

The statistical software package SAS 9.4 (version 6.1; SAS, Cary, NC, USA) was used for the statistical analyses and a two-sided $p$-value below 0.05 was considered statistically significant. Pregnancy characteristics in categorical form were cross-tabulated with both exposure and outcome and compared with the use of chi-square test. In order to quantify the difference in growth in the three exposure groups the mean and dispersion index of the difference between observed and expected gestational age at second trimester scan for each of the three groups was calculated. The odds for accelerated growth ( $>90$ th percentile) or delayed growth $(<10$ th percentile) were calculated based on discrepancy in fetal growth at early second trimester scan, using fetuses with appropriate growth (10th to 90th percentile) as the reference group. The odds of preterm birth were estimated by binary logistic regression analysis and expressed as crude and adjusted odds ratios (aORs) with 95\% confidence intervals (CIs). Adjustments were made for maternal age ( $<$ or $\geq 35$ years), maternal height $(<$ or $\geq 155 \mathrm{~cm})$, BMI $\left(<\right.$ or $\geq 30 \mathrm{~kg} / \mathrm{m}^{2}$ ), non-Nordic origin (yes/no), primiparity (yes/no), smoking (yes/no), IVF (yes/no), pre-gestational diabetes mellitus (yes/no), chronic hypertension (yes/no) and male fetal gender. The selection of potential confounders recorded at the first antenatal visit, was based on directed acyclic graphs (DAGs) (Figure S1). Lastly, the multivariable risks and their distribution due to the presence of quantitative covariates (i.e. mean predictive value and standard deviation) were calculated for all categories of preterm birth based on a regression model for delayed, appropriate and accelerated fetal growth.

\section{Ethical approval}

The study was approved by the Regional Ethical Review Authority in Stockholm, Sweden (Dnr 2014/2179-31/1). The need for written or oral informed consent for participation in the study was waived since all collected data were depersonalized prior to the analysis.

\section{Patient and public involvement}

There was no patient or public involvement in the design, conduct, reporting or dissemination plans of our research study.

\section{Results}

The characteristics of the study population according to gestational age at birth are presented in Table 1. Overall, 2838 (4\%) of all pregnancies ended preterm; 2460 (3.5\%) pregnancies ended between 32 and 37 weeks of gestation while $0.5 \%$ ended before 32 weeks of gestation. More specifically, $40.6 \%$ of overall preterm deliveries were initiated by clinicians (medically induced) and 59.4\% started spontaneously. Mothers delivering preterm were more often pregnant through IVF, born outside the Nordic countries, were multiparous, overweight or obese, of short height or were treated for chronic hypertension.

Based on the information on biometric measurements, 7091 (10.1\%) of fetuses had BPD growth more than the 90th percentile at the second trimester ultrasonic scans. In $55,571(79.8 \%)$ of fetuses, the growth was between 10th and 90th percentile, while $10.1 \%$ of fetuses had a BPD growth smaller than expected $(<10$ th percentile). Mothers whose fetus had exhibited accelerated fetal growth at second trimester were more often younger 
Table 1 Baseline characteristics of mothers according to gestational age at birth. ( $N=69,617$ births)

\begin{tabular}{|c|c|c|c|c|c|}
\hline Characteristics & $\begin{array}{l}\text { Very preterm births }{ }^{a} \\
(n=378)\end{array}$ & $\begin{array}{l}\text { Moderate preterm births }{ }^{b} \\
(n=2460)\end{array}$ & $\begin{array}{l}\text { Term births } \\
(n=62,971)\end{array}$ & $\begin{array}{l}\text { Postterm births }{ }^{d} \\
(n=3808)\end{array}$ & $P$-value \\
\hline Maternal age older than $35 y$ & $197(52.1)$ & $1121(45.6)$ & $28,470(45.2)$ & $1789(46.9)$ & 0.009 \\
\hline Short maternal height $(<155 \mathrm{~cm})$ & $17(4.5)$ & $98(3.9)$ & $1508(2.4)$ & $57(1.5)$ & $<0.0001$ \\
\hline Obesity (BMI $\geq 30 \mathrm{~kg} / \mathrm{m}^{2}$ ) & $40(10.9)$ & $219(9.4)$ & $4055(6.7)$ & $271(7.5)$ & $<0.0001$ \\
\hline Non- Nordic origin & $88(25.8)$ & $413(19.6)$ & $10,312(18.4)$ & $525(15.9)$ & $<0.0001$ \\
\hline Primiparity & $182(48.1)$ & $1187(48.2)$ & $36,197(57.5)$ & $1629(42.8)$ & $<0.0001$ \\
\hline Smoking & $15(4.1)$ & $82(3.4)$ & $1575(2.5)$ & $82(2.2)$ & 0.007 \\
\hline In vitro fertilization (IVF) & $45(11.9)$ & $228(9.3)$ & $3993(6.3)$ & $168(4.4)$ & $<0.0001$ \\
\hline Chronic hypertension & $11(2.9)$ & $51(2.1)$ & $556(0.9)$ & $27(0.7)$ & $<0.0001$ \\
\hline Pre-gestational diabetes mellitus & $1(0.2)$ & $28(1.1)$ & $116(0.2)$ & 0 & $<0.0001$ \\
\hline Male fetal gender & $208(55.0)$ & $1334(54.2)$ & $31,959(50.7)$ & $2028(53.3)$ & $<0.0001$ \\
\hline
\end{tabular}

${ }^{a}$ Very preterm birth: gestational age less than 32 weeks

${ }^{\mathrm{b}}$ Moderate preterm birth: gestational age between $32+0$ and $36+6$

'Term birth: gestational age between $37+0$ and $41+6$

${ }^{\mathrm{d}}$ Postterm birth: gestational age 42 weeks or more

and multiparous compared to those whose fetus had appropriate fetal growth. Male fetuses at second trimester were more often larger in size than female fetuses (Table 2).

Compared to fetuses with appropriate growth at early second trimester ultrasound, fetuses with accelerated growth had a $40 \%$ increased risk for prematurity, both what regards moderate as well as very preterm birth. The association between fetal growth and overall and moderate preterm birth remained unchanged despite adjusting for maternal characteristics, pre-pregnancy diabetes, chronic hypertension and fetal gender (Table 3). However, the risk for very preterm birth did not reach statistical significance after adjustment.
Medically induced labor was observed in $40.6 \%$ of preterm births with the odds of prematurity being increased among fetuses with accelerated growth compared to fetuses with appropriate growth at second trimester scan. Even after adjustment for relevant confounders, the odds remained elevated (Table 4).

On the other hand, 6955 fetuses were smaller than expected at second trimester scan (growth less than 10th percentile). Among them, 234 fetuses were born preterm (31 were born very preterm and 203 moderate preterm). Fetuses that experienced delayed growth in early pregnancy, had a decreased risk for preterm birth (aOR 0.84; 95\% CI 0.71-0.97), an effect seen mostly among spontaneously preterm born infants (Tables 3 and 4).

Table 2 Baseline characteristics according to fetal growth in early pregnancy. ( $N=69,617$ births)

\begin{tabular}{|c|c|c|c|c|}
\hline Characteristics & $\begin{array}{l}\text { Accelerated fetal growth } \\
(n=7091)\end{array}$ & $\begin{array}{l}\text { Appropriate fetal growth } \\
(n=55,571)\end{array}$ & $\begin{array}{l}\text { Delayed fetal growth } \\
(n=6955)\end{array}$ & $P$-value \\
\hline Maternal age older than $35 \mathrm{y}$ & $3117(43.9)$ & $25,108(45.2)$ & $3352(48.2)$ & $<0.0001$ \\
\hline Short maternal height $(<155 \mathrm{~cm})$ & $143(2.0)$ & $1367(2.4)$ & $170(2.4)$ & 0.13 \\
\hline Obesity (BMI $\geq 30 \mathrm{~kg} / \mathrm{m}^{2}$ ) & $440(6.5)$ & $3658(6.9)$ & $487(7.3)$ & 0.28 \\
\hline Non- Nordic origin & $1092(17.7)$ & $9043(18.4)$ & $1203(18.9)$ & 0.64 \\
\hline Primiparity & $3409(48.1)$ & $31,269(56.3)$ & $4517(64.9)$ & $<0.0001$ \\
\hline Smoking & $177(2.5)$ & $1538(2.5)$ & $210(3.0)$ & 0.03 \\
\hline In vitro fertilization (IVF) & $443(6.2)$ & $3649(6.5)$ & $342(4.9)$ & $<0.0001$ \\
\hline Chronic hypertension & $62(0.9)$ & $523(0.9)$ & $60(0.9)$ & 0.45 \\
\hline Pre-gestational diabetes mellitus & $12(0.2)$ & $116(0.2)$ & $17(0.2)$ & 0.75 \\
\hline Male fetal gender & $4988(70.4)$ & $28,179(50.7)$ & $2362(33.9)$ & $<0.0001$ \\
\hline $\begin{array}{l}\text { Difference in growth } \\
\text { mean (dispersion index) }\end{array}$ & $5.14(0.45)$ & $-0.63(-7.29)$ & $-6.56(-0.34)$ & $<0.0001$ \\
\hline
\end{tabular}

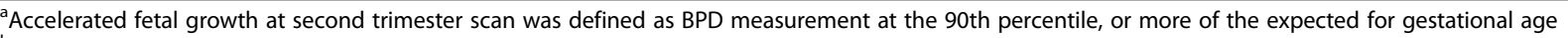
${ }^{\mathrm{b}}$ Appropriate fetal growth at second trimester scan was defined as BPD measurement between 10th - 90th percentile of the expected for gestational age 'Delayed fetal growth at second trimester scan was defined as BPD measurement at the 10th percentile, or less of the expected for gestational age

${ }^{\mathrm{d} D i f f e r e n c e ~ b e t w e e n ~ o b s e r v e d ~ a n d ~ e x p e c t e d ~ g e s t a t i o n a l ~ a g e ~ a t ~ s e c o n d ~ t r i m e s t e r ~ s c a n ~}$ 
Table 3 Growth in early pregnancy and risk of preterm birth, very preterm and moderate preterm birth. ( $N=2838$ births)

\begin{tabular}{|c|c|c|c|c|c|c|c|c|c|}
\hline \multirow{3}{*}{$\begin{array}{l}\text { Growth at } \\
\text { second } \\
\text { trim scan }\end{array}$} & \multicolumn{3}{|c|}{$\begin{array}{l}\text { All preterm births } \\
(n=2838)\end{array}$} & \multicolumn{3}{|c|}{$\begin{array}{l}\text { Very preterm births } \\
(n=378)\end{array}$} & \multicolumn{3}{|c|}{$\begin{array}{l}\text { Moderate preterm births } \\
(n=2460)\end{array}$} \\
\hline & \multirow{2}{*}{$\begin{array}{l}\text { No. of } \\
\text { women }\end{array}$} & \multicolumn{2}{|c|}{ Odds ratio $(95 \% \mathrm{Cl})$} & \multirow{2}{*}{$\begin{array}{l}\text { No. of } \\
\text { women }\end{array}$} & \multicolumn{2}{|c|}{ Odds ratio $(95 \% \mathrm{Cl})$} & \multirow{2}{*}{$\begin{array}{l}\text { No. of } \\
\text { women }\end{array}$} & \multicolumn{2}{|c|}{ Odds ratio $(95 \% \mathrm{Cl})$} \\
\hline & & Crude & Adjusted $^{d}$ & & Crude & Adjusted $^{d}$ & & Crude & Adjusted $^{d}$ \\
\hline $\begin{array}{l}\text { Accelerated } \\
\text { fetal growth }\end{array}$ & 389 & $1.39(1.25-1.56)^{*}$ & $1.36(1.20-1.54)^{*}$ & 52 & $1.38(1.01-1.86)^{* *}$ & $1.33(0.96-1.83)^{* *}$ & 337 & $1.39(1.24-1.57)^{*}$ & $1.36(1.18-1.55)^{\prime}$ \\
\hline $\begin{array}{l}\text { Appropriate } \\
\text { fetal growth }\end{array}$ & 2215 & Ref & Ref & 295 & Ref & Ref & 1920 & Ref & Ref \\
\hline $\begin{array}{l}\text { Delayed } \\
\text { fetal growth }\end{array}$ & 234 & $0.85(0.73-0.96)^{*}$ & $0.84(0.71-0.97)^{*}$ & 31 & $0.84(0.58-1.21)^{* * *}$ & $0.73(0.47-1.12)^{* * *}$ & 203 & $0.84(0.72-0.97)^{*}$ & $0.85(0.73-1.00)^{7}$ \\
\hline
\end{tabular}

${ }^{2}$ Accelerated fetal growth at second trimester scan was defined as BPD measurement at the 90th percentile, or more of the expected for gestational age

${ }^{5}$ Appropriate fetal growth at second trimester scan was defined as BPD measurement between 10th -90th percentile of the expected for gestational age

'Delayed fetal growth at second trimester scan was defined as BPD measurement at the 10th percentile, or less of the expected for gestational age

${ }^{d}$ Adjusted OR for maternal age older than 35 yrs., short maternal height $<155 \mathrm{~cm}, \mathrm{BMI} \geq 30 \mathrm{~kg} / \mathrm{m}^{2}$, non-Nordic origin, primiparity, smoking, IVF, pregestational diabetes mellitus, chronic hypertension and male fetal gender

$p<0.0001$

$p<0.05$

$p>0.05$

Lastly, after adjusting for relevant confounders the mean predictive value of preterm birth for fetuses with delayed, appropriate and accelerated growth was estimated to be $0.031,0.038$ and 0.053 respectively (Supplementary Table).

\section{Discussion}

In this registry-based study, we have demonstrated that early accelerated fetal growth, reflected by an increase in BPD measurement estimated by ultrasound, was associated with increased odds of preterm birth. The effect estimates remained unchanged even after stratification according to timing, as well as to type of preterm birth (i.e. very preterm vs moderate preterm birth and medically induced vs spontaneous preterm birth). These findings underline the importance of accelerated fetal growth in early pregnancy and the potential association to complications later in pregnancy.

In accordance with our study, Pedersen et al. demonstrated an increased risk for prematurity among fetuses with accelerated growth; OR 3.27 (95\% CI, 0.99-10.73) for very preterm births 22-33 weeks and OR 2.30 (95\% CI, 1.15-4.59) for moderate preterm births [10]. Similarly to our study, their population included a relatively small number of pregnant women suffering from very preterm birth, which could partly explain why the results did not reach statistical significance $(p=0.074)$ [10]. Additionally, the association between increased birthweight and elevated risk of preterm birth has been previously described, but without focus on growth in early pregnancy $[6,7]$. In the cohort of 1 million births recorded in the Swedish Medical Birth Register, Morken et al. observed increased risk for birth between 34 and 36 weeks of gestation (OR 1.6, 95\% CI 1.5-1.7) among infants with larger birthweight than the population mean [7]. Similarly, Gaillard et al., observed an increased risk for overall and spontaneous preterm birth among fetuses with larger head circumference in second trimester [12]. On the contrary, in the study performed by Partap et al.,

Table 4 Growth in early pregnancy and risk of preterm birth either spontaneous or medically induced. ( $N=2838$ births)

\begin{tabular}{|c|c|c|c|c|c|c|}
\hline \multirow[t]{3}{*}{$\begin{array}{l}\text { Growth at second trim } \\
\text { scan }\end{array}$} & \multicolumn{3}{|c|}{$\begin{array}{l}\text { Spontaneous preterm birth } \\
(n=1687)\end{array}$} & \multicolumn{3}{|c|}{$\begin{array}{l}\text { Medically induced preterm birth } \\
(n=1151)\end{array}$} \\
\hline & \multirow{2}{*}{$\begin{array}{l}\text { No. of } \\
\text { women }\end{array}$} & \multicolumn{2}{|c|}{ Odds ratio $(95 \% \mathrm{Cl})$} & \multirow{2}{*}{$\begin{array}{l}\text { No. of } \\
\text { women }\end{array}$} & \multicolumn{2}{|c|}{ Odds ratio $(95 \% \mathrm{Cl})$} \\
\hline & & Crude & Adjusted $^{\text {d }}$ & & Crude & Adjusted $^{\mathrm{d}}$ \\
\hline Accelerated fetal growth ${ }^{\mathrm{a}}$ & 234 & $1.39(1.21-1.61)^{*}$ & $1.35(1.15-1.58)^{*}$ & 155 & $1.37(1.15-1.63)^{*}$ & $1.34(1.11-1.63)^{* *}$ \\
\hline Appropriate fetal growth ${ }^{\mathbf{b}}$ & 1325 & Ref & Ref & 890 & Ref & Ref \\
\hline Delayed fetal growth ${ }^{c}$ & 128 & $0.78(0.64-0.92)^{*}$ & $0.78(0.63-0.96)^{*}$ & 106 & $0.95(0.77-1.16)^{* * *}$ & $0.91(0.72-1.15)^{* * *}$ \\
\hline
\end{tabular}

${ }^{a}$ Accelerated fetal growth at second trimester scan was defined as BPD measurement at the 90th percentile, or more of the expected for gestational age

${ }^{\mathrm{b}}$ Appropriate fetal growth at second trimester scan was defined as BPD measurement between 10th - 90th percentile of the expected for gestational age

'Delayed fetal growth at second trimester scan was defined as BPD measurement at the 10th percentile, or less of the expected for gestational age

${ }^{\mathrm{d}}$ Adjusted OR for maternal age older than $35 \mathrm{yrs}$., short maternal height $<155 \mathrm{~cm}, \mathrm{BMI} \geq 30 \mathrm{~kg} / \mathrm{m}^{2}$, non-Nordic origin, primiparity, smoking, IVF, chronic

hypertension, pre-gestational diabetes mellitus and male fetal gender

${ }^{*} p<0.0001$

${ }^{* *} p<0.01$

${ }^{* * *} p=0.05$ 
the authors observed an inverse relationship between growth velocity of femur length in second trimester and risk of spontaneous preterm birth [13]. Another finding of our study was the decreased risk for prematurity observed among fetuses with delayed fetal growth at the ultrasound scan of the second trimester. Despite adjusting for chronic hypertension, preeclampsia and other potential risk factors for medically induced prematurity, the risk of prematurity for fetuses with delayed growth remained nevertheless lower compared to the reference group (i.e., fetuses with normal growth). One possible explanation of this finding is the exclusion of pregnancies with fetal aneuploidy, congenital anomalies and fetal demise from the study population according to study design. Since the prior conditions have been associated to delayed fetal growth [14-16], it is not surprising that this exclusion might deflate the expected rates of preterm birth in this subgroup of fetuses.

The incidence of preterm birth estimated in our study is in accordance with the reported national rates in Sweden and other Nordic countries [7, 17, 18]. However, in our study, $40.6 \%$ of preterm births were classified as medically initiated births, compared to 35 and 25\% reported in previous Swedish studies [7, 17]. These variations could be the result of methodological differences in study design such as different cut-offs of preterm birth employed, or different outcome definitions such as that of premature preterm rupture of membranes (pPROM) [7, 17]. Furthermore, the higher rates of medically induced preterm births observed in our study could reflect increasing rates of medical intervention over time, a trend that has also been reported in other settings [18-21].

Although the exact pathophysiological mechanism behind our findings still remains unknown, a number of possible hypotheses associated to the onset of labor have been proposed. One of the theories to explain the timing of birth refers to prelabor mechanical distention and stretching of the myometrium [22]. The overdistention of the uterus leads to increased expression of contractionassociated proteins (such as connexin-43), and initiate the necessary biochemical steps towards coordinated and forceful contractions [23-25]. Based on the physiology of uterine contractions, it is thus reasonable to assume that accelerated fetal growth could increase the distension demands posed on the uterus to a greater degree than during normal fetal growth and subsequently trigger spontaneous preterm labor. The theory is also in line with the contrasting finding of preterm birth and delayed fetal growth. One can only assume that fetuses smaller than expected, do not grow at the same velocity and probably do not reach equally large birthweights as fetuses with accelerated growth, decreasing thereby the risk of triggering or activating the labor system at a preterm stage.
One of the major strengths of our study is the accurate estimation of gestational age based on ultrasonographic measurements at the first trimester of pregnancy and not on the self-reported last menstrual period of the participating women which can often be unreliable. Furthermore, we attempted to explore growth velocity based on the measurements of only one biometric characteristic (i.e., BPD), since it was the only biophysical parameter that was readily available both at first and second trimester scan. The latter, in addition to the possibility of calculating gestational age solely based on BPD measurements also justifies why the formula by Selbing was employed, enabling us at the same time to avoid uncertainty introduced by utilizing different calculation methods. Another major strength lies on the large sample size with detailed information collected prospectively, which limits the risk for recall bias. The large cohort size in the study, made it possible to stratify the analysis in spontaneous and medically induced groups, as well as in moderately preterm and very preterm groups and therefore explore rare outcomes. Furthermore, Sweden has a long tradition of valid registries entailing routinely collected, comprehensive and accurate data especially in the perinatal field. In addition, the publicly funded healthcare system of the country enables equal access to prenatal healthcare and early identification and possibly preventive intervention against preterm birth. That makes Sweden an appropriate model country to explore the research question. Lastly, since all ultrasound units in Sweden follow the same professional standards, we can only assume that the performance variation of the ultrasound examiners is restricted [8].

The present study is however not void of limitations. First and foremost, we lack information on the paternal characteristics, which along with the maternal might influence fetal growth. We also lack information on potential risk factors associated to the outcome (i.e. preterm birth) such as prior preterm birth, cervical length, uterine fibroid or malformations and genitourinary infections. However, all of these covariates are not anticipated, according to the literature, to be unevenly distributed between the groups of interest, i.e. the reference group of fetuses with appropriate growth and the comparison group of fetuses with accelerated growth. Furthermore, as we were obliged to restrict our population to pregnancies where CUB was performed and a fraction of the population did not perform first trimester sonographic scans, a potential selection bias related to advanced maternal age cannot entirely be ruled out. We have therefore tried to account for it by adjusting for advanced maternal age in the logistic regression analysis. However, despite the fact that the CUB scan is optional in Sweden, many women choose nevertheless to undergo ultrasound examination both in the first and second 
trimester making our results applicable in the clinical setting. There is of course the risk that fetal growth velocity was already affected at the time of the dating of the pregnancy (gestational week 11-14), on which the calculation of gestational age was based. By including in the performed risk analyses detailed information on maternal, pregnancy and fetal characteristics, known to affect both first-trimester growth and the risk of preterm birth [26-31] that scenario was accounted for. Finally, our population comes mainly from the urban area of the capital of Sweden (Stockholm) and its composition corresponds to that of other large cities, potentially affecting the generalizability of our findings in the wider birthing population.

\section{Conclusion}

Accelerated fetal growth during early gestation is associated with an increased risk of preterm birth overall, as well as with medically induced and spontaneous preterm birth. There is currently no recommendation on the management of pregnancies with accelerated fetal growth early in pregnancy. Identification of pregnancies at risk could allow proper interventions such as counselling on maternal nutrition and physical activity or even introduction of more appropriate surveillance considering the risk for prematurity. Further research on the topic is therefore warranted.

\section{Supplementary Information}

The online version contains supplementary material available at https://doi. org/10.1186/s12884-020-03458-x.

Additional file 1: Figure S1. Directed acyclic graph (DAG) showing the relation between covariates included in the analyses and exposure (accelerated early fetal growth) and outcome (preterm birth).

Additional file 2: Supplementary Table. Growth in early pregnancy and multivariable risk of overall preterm birth and its subcategories (very preterm, moderate preterm, spontaneous preterm and medically induced preterm birth).

\section{Abbreviations}

ICD: International Statistical Classification of diseases-10th edition; BPD: Biparietal diameter; OR: Odds ratio; Cl: Confidence interval; BMI: Body mass index; IVF: In vitro fertilization; CUB: Combined ultrasound and biochemical screening test

\section{Acknowledgements}

Not applicable.

\section{Authors' contributions}

MS has been responsible for the design of the study and data collection. MS and $\mathrm{EE}$ have equally contributed in data analysis, the interpretation of the results and drafting of the manuscript. AKW has assisted in drafting the manuscript and has critically revised it. All authors have approved the final version submitted.

\section{Funding}

The authors received no specific funding for this work. EE has a part-time research position funded by Uppsala University Hospital (grant no. ALF 1040530/2019). The funder had no role in study design, data collection and analysis, decision to publish, or preparation of the manuscript. Open Access funding provided by Uppsala University.

\section{Availability of data and materials}

The datasets generated and analysed during the current study are not publicly available and cannot be uploaded at any website due to the risk of compromising the individual privacy of participants. On the other hand, the data is available from the responsible department upon reasonable request. Any interested parties are welcome to contact the authors, who will then fill out the agreements necessary when sharing data and after approval by the Regional Ethics Board in Stockholm, Sweden. All data regarding the current study are available on request to the Department of Women's and Children's Health, Karolinska Institutet.

\section{Ethics approval and consent to participate}

The study was approved by the Regional Ethical Review Authority in Stockholm, Sweden (Dnr 2014/2179-31/1). The need for written or oral informed consent for participation in the study was waived since all collected data were depersonalized prior to the analysis. Administrative permission was acquired by our team to access the data used in this research from the clinics in Region Stockholm/Gotland. No licenses were required.

\section{Consent for publication}

Not applicable.

\section{Competing interests}

EE has received lecture fee from Gideon Richter outside the submitted work. The other authors have no conflicts of interest to declare.

\section{Author details}

'Department of Children's and Women's Health, Uppsala University, Uppsala University Hospital, SE-751 85 Uppsala, Sweden. ${ }^{2}$ Clinical Epidemiology Unit, Department of Medicine Solna, Karolinska University Hospital and Institutet, Stockholm SE-17176, Sweden.

Received: 24 June 2020 Accepted: 25 November 2020

Published online: 09 December 2020

References

1. Chang HH, Larson J, Blencowe H, Spong CY, Howson CP, Cairns-Smith S, et al. Preventing preterm births: analysis of trends and potential reductions with interventions in 39 countries with very high human development index. Lancet. 2013;381(9862):223-34.

2. Liu L, Oza S, Hogan D, Chu Y, Perin J, Zhu J, et al. Global, regional, and national causes of under-5 mortality in 2000-15: an updated systematic analysis with implications for the sustainable development goals. Lancet. 2016:388(10063):3027-35.

3. Blencowe H, Cousens S, Chou D, Oestergaard M, Say L, Moller AB, et al. Born too soon: the global epidemiology of 15 million preterm births. Reprod Health. 2013;10(Suppl 1):S2.

4. Lawn JE, Cousens S, Zupan J, Lancet Neonatal Survival Steering T. 4 million neonatal deaths: when? where? why? Lancet. 2005;365(9462):891-900.

5. Petrini JR, Dias T, McCormick MC, Massolo ML, Green NS, Escobar GJ. Increased risk of adverse neurological development for late preterm infants. J Pediatr. 2009;154(2):169-76.

6. Lackman F, Capewell V, Richardson B, daSilva O, Gagnon R. The risks of spontaneous preterm delivery and perinatal mortality in relation to size at birth according to fetal versus neonatal growth standards. Am J Obstet Gynecol. 2001;184(5):946-53.

7. Morken NH, Kallen K, Jacobsson B. Fetal growth and onset of delivery: a nationwide population-based study of preterm infants. Am J Obstet Gynecol. 2006;195(1):154-61.

8. Simic M, Wikstrom AK, Stephansson O. Accelerated fetal growth in early pregnancy and risk of severe large-for-gestational-age and macrosomic infant: a cohort study in a low-risk population. Acta Obstet Gynecol Scand. 2017;96(10):1261-8.

9. Mook-Kanamori DO, Steegers EA, Eilers PH, Raat H, Hofman A, Jaddoe WW. Risk factors and outcomes associated with first-trimester fetal growth restriction. JAMA. 2010;303(6):527-34

10. Pedersen NG, Wojdemann KR, Scheike T, Tabor A. Fetal growth between the first and second trimesters and the risk of adverse pregnancy outcome. Ultrasound Obstet Gynecol. 2008;32(2):147-54. 
11. Lampl M, Kusanovic JP, Erez O, Espinoza J, Gotsch F, Goncalves L, et al. Early rapid growth, early birth: accelerated fetal growth and spontaneous late preterm birth. Am J Hum Biol. 2009;21(2):141-50.

12. Gaillard R, Steegers EA, de Jongste JC, Hofman A, Jaddoe WW. Tracking of fetal growth characteristics during different trimesters and the risks of adverse birth outcomes. Int J Epidemiol. 2014:43(4):1140-53.

13. Partap U, Sovio U, Smith GC. Fetal growth and the risk of spontaneous preterm birth in a prospective cohort study of nulliparous women. Am J Epidemiol. 2016;184(2):110-9.

14. Sagi-Dain L, Peleg A, Sagi S. First-trimester crown-rump length and risk of chromosomal aberrations-a systematic review and meta-analysis. Obstet Gynecol Surv. 2017;72(10):603-9.

15. Baken L, Benoit B, Koning AHJ, van der Spek PJ, Steegers EAP, Exalto N. First-trimester crown-rump length and embryonic volume of fetuses with structural congenital abnormalities measured in virtual reality: an observational study. Biomed Res Int. 2017;2017:1953076.

16. Mukri F, Bourne T, Bottomley C, Schoeb C, Kirk E, Papageorghiou AT. Evidence of early first-trimester growth restriction in pregnancies that subsequently end in miscarriage. BJOG. 2008;115(10):1273-8.

17. Murray SR, Juodakis J, Bacelis J, Sand A, Norman JE, Sengpiel V, et al. Geographical differences in preterm delivery rates in Sweden: a populationbased cohort study. Acta Obstet Gynecol Scand. 2019:98(1):106-16.

18. Richards JL, Kramer MS, Deb-Rinker P, Rouleau J, Mortensen L, Gissler M, et al. Temporal trends in late preterm and early term birth rates in 6 highincome countries in North America and Europe and association with clinician-initiated obstetric interventions. JAMA. 2016:316(4):410-9.

19. Richter LL, Ting J, Muraca GM, Synnes A, Lim Kl, Lisonkova S. Temporal trends in neonatal mortality and morbidity following spontaneous and clinician-initiated preterm birth in Washington state, USA: a populationbased study. BMJ Open. 2019;9(1):e023004.

20. Stout MJ, Demaree D, Merfeld E, Tuuli MG, Wambach JA, Cole FS, et al. Neonatal outcomes differ after spontaneous and indicated preterm birth. Am J Perinatol. 2018;35(5):494-502.

21. Wong AE, Grobman WA. Medically indicated--iatrogenic prematurity. Clin Perinatol. 2011:38(3):423-39.

22. Adams Waldorf KM, Singh N, Mohan AR, Young RC, Ngo L, Das A, et al. Uterine overdistention induces preterm labor mediated by inflammation: observations in pregnant women and nonhuman primates. Am J Obstet Gynecol. 2015;213(6):830.e1-e19.

23. Garfield RE, Kannan MS, Daniel EE. Gap junction formation in myometrium: control by estrogens, progesterone, and prostaglandins. Am J Phys. 1980; 238(3):C81-9.

24. Terzidou V, Sooranna SR, Kim LU, Thornton S, Bennett PR, Johnson MR. Mechanical stretch up-regulates the human oxytocin receptor in primary human uterine myocytes. J Clin Endocrinol Metab. 2005;90(1): 237-46.

25. Maradny EE, Kanayama N, Halim A, Maehara K, Terao T. Stretching of fetal membranes increases the concentration of interleukin-8 and collagenase activity. Am J Obstet Gynecol. 1996;174(3):843-9.

26. Peelen MJ, Kazemier BM, Ravelli AC, De Groot CJ, Van Der Post JA, Mol BW, et al. Impact of fetal gender on the risk of preterm birth, a national cohort study. Acta Obstet Gynecol Scand. 2016;95(9):1034-41.

27. Ion RC, Wills AK, Bernal AL. Environmental tobacco smoke exposure in pregnancy is associated with earlier delivery and reduced birth weight. Reprod Sci. 2015;22(12):1603-11.

28. Waldenstrom U, Cnattingius S, Vixner L, Norman M. Advanced maternal age increases the risk of very preterm birth, irrespective of parity: a populationbased register study. BJOG. 2017;124(8):1235-44.

29. Van Leeuw V, Leroy C, Englert Y, Zhang WH. Effect of maternal origin on the association between maternal height and risk of preterm birth in Belgium: a retrospective observational cohort study. BMJ Open. 2018;8(4): e020449.

30. Kim SS, Mendola P, Zhu Y, Hwang BS, Grantz KL. Spontaneous and indicated preterm delivery risk is increased among overweight and obese women without prepregnancy chronic disease. BJOG. 2017;124(11):1708-16.

31. Goldenberg RL, Culhane JF, lams JD, Romero R. Epidemiology and causes of preterm birth. Lancet. 2008;371(9606):75-84.

\section{Publisher's Note}

Springer Nature remains neutral with regard to jurisdictional claims in published maps and institutional affiliations.

\section{Ready to submit your research? Choose BMC and benefit from:}

- fast, convenient online submission

- thorough peer review by experienced researchers in your field

- rapid publication on acceptance

- support for research data, including large and complex data types

- gold Open Access which fosters wider collaboration and increased citations

- maximum visibility for your research: over $100 \mathrm{M}$ website views per year

At BMC, research is always in progress.

Learn more biomedcentral.com/submissions 